\title{
Effect of alcohol dehydrogenase 1C (ADH1C) genotype on vitamin A restriction and marbling in Korean native steers
}

\author{
Dong Qiao Peng ${ }^{1,2}$, U Suk Jung ${ }^{1}$, Jae Sung Lee ${ }^{1,2}$, Won Seob Kim ${ }^{1,2}$, Yong Ho Jo ${ }^{1,2}$, Min Jeong Kim ${ }^{1}$, \\ Young Kun $\mathrm{Oh}^{3}$, Youl Chang Baek ${ }^{3}$, Seong Gu Hwang ${ }^{4}$, and Hong Gu Lee ${ }^{1,2, *}$
}

\begin{abstract}
* Corresponding Author: Hong Gu Lee Tel: +82-2-450-0523, Fax: +82-2-455-1044, E-mail: hglee66@konkuk.ac.kr
\end{abstract}

'Department of Animal Science and Technology, College of Animal Bioscience and Technology, Konkuk University, Seoul 05029, Korea

${ }^{2}$ Team of An Educational Program for Specialists in Global Animal Science, Brain Korea 21 Plus Project, Konkuk University, Seoul 05029, Korea

${ }^{3}$ Animal Nutrition and Physiology team, Department of Animal Biotechnology and Environment, National Institute of Animal Science RDA, Jeonju 54875, Korea ${ }^{4}$ Department of Animal Life and Environment Science, Hankyong National University, Anseong 17579, Korea

Submitted Sept 19, 2016; Revised Dec 4, 2016; Accepted Jan 11, 2017
Objective: This work was to find the correlation of alcohol dehydrogenase 1C (ADH1C) genotype with vitamin A reduction and carcass traits during the vitamin A restriction period. Methods: In study 1, 60 Korean native steers were fed a diet (890 IU/kg) with 8,000 IU and 0 IU of supplemental premix vitamin $\mathrm{A} / \mathrm{kg}$ of dry matter (DM) for control and treatment group, respectively. The levels of serum vitamin A were analyzed through high preparative performance liquid chromatography, and the $\mathrm{ADH} 1 \mathrm{C}$ genotype was analyzed based on polymerase chain reaction-restriction fragment length polymorphism (PCR-RFLP; 78.1\% TT type, 21.9\% TC type); however, $\mathrm{CC}$ type was not found. Then, the interaction between $\mathrm{ADH1C}$ and carcass traits on the vitamin A restriction was investigated in study 2. A total of 136 Korean native steers were fed a diet that included $930 \mathrm{IU} / \mathrm{kg}$ vitamin A of DM.

Results: Serum vitamin A in treatment was reduced to $112.4 \mathrm{IU} / \mathrm{dL}$ in steers with TT type of ADH1C, while for steers with TC type the concentration of serum vitamin A was dropped to $79.5 \mathrm{IU} / \mathrm{dL}(\mathrm{p}<0.1)$ in study 1 . This showed that TC type had the potential to lower serum vitamin A concentration during vitamin A restriction compared to TT type. In study 2 we found that eye muscle area, marbling and carcass weight in Korean native steers with TC type were higher than in steers with TT type $(\mathrm{p}<0.05)$.

Conclusion: The interaction between vitamin A restriction and TC type of $A D H 1 C$ gene could have the potential of increasing the marbling in Korean native steers. These results indicated that steers with TC type of the $A D H 1 C$ gene were more sensitive to the change of serum vitamin A than TT types. Furthermore, this finding has the potential to enable a higher marbling score under the condition of vitamin A restriction in Korean native steers.

Keywords: Vitamin A Restriction; Alcohol Dehydrogenase 1C (ADH1C); Polymerase Chain Reaction-Restriction Fragment Length Polymorphism (PCR-RFLP); Marbling; Korean Native Steers

\section{INTRODUCTION}

In recent years, higher standards of living have led consumers to pay more attention to the quality of beef. High quality beef brings satisfaction to consumers, as well as higher profits to producers. High quality beef is assessed based on the following indicators: marbling score, muscle color, fat color, tightness of meat and flavor [1]. Nowadays, marbling is considered as an indicator of meat quality in the beef quality grading system. It was revealed for the first time that there is a negative correlation between concentration of serum vitamin $\mathrm{A}$ and marbling scores, and thus the restriction of vitamin A tended to increase marbling scores in terms of carcass traits [2]. Also, the study by Oka et al [2] suggested that restriction of vitamin A in the early fattening stage would affect the marbling in Japanese black cattle [2]. Meanwhile, when the vitamin A supplement in feedlot heifers was removed, it was found that marbling was increased without affecting the thickness of 
back fat or animal health [3]. Among numerous factors, genetics can also affect the quality of beef. Marker-assisted management contributes to slaughter performance as well as animal by-products. In addition, it can be inferred that the single nucleotide polymorphism in of alcohol dehydrogenase $1 \mathrm{C}(\mathrm{ADH1C}$ c. $-64 \mathrm{~T}>\mathrm{C})$ is associated with intramuscular fat (IMF) and vitamin A restriction in finishing rations of Angus-cross steers [4]. Many previous studies have shown that alcohol dehydrogenase $1(\mathrm{ADH} 1)$ is a major enzyme in achieving the oxidation from retinol to retinaldehyde in mouse experiments [5]. And retinaldehyde dehydrogenases (RALDH) oxidize retinaldehyde to retinoic acid, primarily by RADLH1 [6]. In previous studies, marbling in TT type of ADH1C gene was higher than TC and CC type during the 5 months restriction of vitamin A in Angus crossbred steers [4]. It has also been found that concentration of serum vitamin $\mathrm{A}$ was affected by the time of vitamin A restriction. From this, it could be inferred that serum vitamin A was also affected by the gene of $A D H 1 C$. However, the association was not definite in Korean native steers. Thus, the genotype of ADH1C in Korean native steers needs to be investigated. Meanwhile, when fed a diet with vitamin A restriction, the effect of vitamin A restriction and $\mathrm{ADH1C}$ genotype in serum vitamin A and carcass traits needs to be assessed.

\section{MATERIAL AND METHODS}

\section{Animals and management}

All procedures involving animals were approved by the Animal Care and Use Committee of Konkuk University prior to the experiments (Certificate No: KU16134). A total of 60 Korean native steers were used for study 1 , and were fed a diet (890 IU/kg vita$\min$ A) based on corn and corn flake. The Korean native steers used in this study were from many herds and many sires. The groups contained 8,000 IU and 0 IU of supplemental premix vitamin $\mathrm{A} / \mathrm{kg}$ of dry matter $(\mathrm{DM})$, respectively. The experiment was conducted during the fattening period in Korean native steers (from 15 to 24 months of age), and the composition of feedstuff nutrient in study 1 is shown in Table 1. Blood samples were collected from steers for each month during the period of the experiment. In study 2, 136 Korean native steers were fed a vitamin A restricted diet (0.93 IU/g vitamin A) during the experiment period (from 14 to 21 months age), the nutrient composition of which is shown in Table 1. While the feedstuff nutrient composition of vitamin A restriction in study 2 is not exactly the same as that in study 1 , a similar level and low level of feedstuff vitamin A was still maintained. During the experiment period, the concentration of vitamin A in feedstuff was fed as described in Table 1. After the restriction period, the concentration of vitamin A was changed to a high level again until slaughter in order to obtain better quality beef. The carcass traits were measured after slaughter at the age of 30 months.

Preparation of stock solutions and samples
Table 1. Feedstuff nutrient composition of vitamin A restriction in studies 1 and 2

\begin{tabular}{lccc}
\hline \multirow{2}{*}{ Nutrient } & \multicolumn{2}{c}{ Study 1 } & \multirow{2}{*}{ Study 2 } \\
\cline { 2 - 3 } & Control & Treatment & \\
\hline DM (\%) & 87.74 & 87.80 & 88.19 \\
Crude protein (\% DM) & 15.96 & 15.95 & 14.74 \\
Crude fat (\% DM) & 3.52 & 3.44 & 4.15 \\
Crude ash (\% DM) & 8.06 & 8.23 & 7.11 \\
Neutral detergent fiber (\% DM) & 31.62 & 33.23 & 23.81 \\
Acid detergent fiber (\% DM) & 14.26 & 14.38 & 9.89 \\
Crude fiber (\% DM) & 10.90 & 11.05 & 8.28 \\
Calcium (\% DM) & 0.95 & 0.98 & 0.91 \\
Phosphorus (\% DM) & 0.52 & 0.58 & 0.54 \\
Non-fiber carbohydrate (\% DM) & 36.15 & 35.10 & 49.70 \\
Total digestible nutrients (\% DM) & 82.85 & 82.37 & 84.39 \\
Vitamin A (IU/kg) & $8,890.00$ & 890.00 & 930.00 \\
\hline
\end{tabular}

DM, dry matter.

Blood was collected from the jugular vein of steer by serum tube (BD Vacutainer, Plymouth, UK), then wrapped with tin foil and placed in the ice box before arriving at the lab. Then, blood samples were centrifuged at $3,500 \mathrm{rpm}$ for $15 \mathrm{~min}$ at $4^{\circ} \mathrm{C}$, moved the serum into brown $1.5 \mathrm{~mL}$ of brown micro tube, and finally stored in freezer $\left(-80^{\circ} \mathrm{C}\right)$ before use.

Then, 0.04\% 2.6-di-tert-butyl-4-methylphenol (BHT, SigmaAldrich cat. No. B1378, Yongin, Korea) ethanol solution and $0.04 \%$ BHT hexane solution were prepared for the analysis of serum vitamin A (retinol). We took retinyl acetate $(>99 \%$, SigmaAldrich cat. No. R7882-1g, Korea) as the internal standard. The stock solution of retinyl acetate was made with the concentration of $1 \mathrm{mg}$ retinyl acetate $1 \mathrm{~mL} 0.04 \%$ BHT-ethanol solution. This is followed by diluting to $25 \mu \mathrm{g}$ retinyl acetate/ $1 \mathrm{~mL} 0.04 \%$ BHTethanol solution as the working solution during the analysis of serum vitamin A. In addition, the ethanol, methanol and hexane needed in this study were required to be high preparative performance liquid chromatography (HPLC) grade.

\section{Serum vitamin A analysis}

Serum samples were removed from the freezer and thawed at room temperature, then $200 \mu \mathrm{L}$ of serum and $20 \mu \mathrm{L}$ of internal standard working solution were transferred to a $2 \mathrm{~mL}$ micro tube. Next, $200 \mu \mathrm{L}$ distilled water and $400 \mu \mathrm{L}$ of $0.04 \%$ BHT-ethanol solution were added. After vortexing vigorously, $800 \mu \mathrm{L}$ of $0.04 \%$ BHT-hexane solution was added and vortexed again vigorously and centrifuged at 3,500 g for $10 \mathrm{~min}$ at $4^{\circ} \mathrm{C}$. Next, $700 \mu \mathrm{L}$ of hexane was transferred into $1.5 \mathrm{~mL}$ of brown micro tube followed by evaporating hexane completely under $\mathrm{N}_{2}$ gas blowing by dry block bath (MG-2200, EYELA, Tokyo, Japan). The sample was dissolved again with 95\% methanol after evaporation, and mixed by vortex. Three control internal standard solutions were made again by mixing internal standard working solution $20 \mu \mathrm{L}$ and $0.04 \%$ BHT-ethanol $480 \mu \mathrm{L}$ into brown micro tube. Finally the solution was transferred to LC vial (G004-HP-D, Infochroma ag, 
Goldau, Switzerland) after filtering using the syringe filter (PES, $0.33 \mathrm{~mm}, 0.22 \mu \mathrm{m}$, SLGP033RB, Millex, Darmstadt, Germany), then concentration of serum vitamin A was analyzed using a HPLC machine (Agilent 1100 Series, Deutschland, Germany) with the reverse phase column of Stainless steel Novapak C18 $4 \mu \mathrm{m}$ (3.9 mm ID $\times 150 \mathrm{~mm}$, Waters, Dublin, Ireland). The 95\% methanol was used as the mobile phase and the flow rate was $1 \mathrm{~mL} / \mathrm{min}$. Serum vitamin A (retinol) was absorbed at $325 \mathrm{~nm}$ by DAD-UV lamp and the column was set at $20^{\circ} \mathrm{C}$. We obtained the area of retinol and retinyl acetate from samples using the HPLC program in computer.

The standard curve was made by diluting the retinol (>99\%, Sigma-Aldrich cat. No. R7632-25mg, Korea) to different concentrations $(12.5,6.25,3.13,1.56,0.78,0.39,0.20,0.10,0.05 \mu \mathrm{g} / \mathrm{mL})$ along with the $1 \mu \mathrm{g} / \mathrm{mL}$ of internal standard.

\section{DNA extraction from beef}

The DNA was extracted from beef using the manual method. Beef was cut into small slices and placed into a $1.5 \mathrm{~mL}$ tube. The $300 \mu \mathrm{L}$ tissue lysis buffer (TL) buffer, contained $1 \mathrm{M}$ Tris- $\mathrm{Cl} \mathrm{PH}$ 8.0, 0.5 M ethylenediaminetetraacetic acid (EDTA) pH 8.0, $5 \mathrm{M}$ $\mathrm{NaCl}, 10 \%$ sodium dodecyl sulfate and distilled water) was added and mixed by inverting. Then, $5 \mu \mathrm{L}$ proteinase $\mathrm{K}$ was added (20 mg/mL, G-spin Total DNA extraction Kit, iNtRON Biotechnology, Seongnam, Korea), followed by incubation at $56^{\circ} \mathrm{C}$ overnight. Next, $300 \mu \mathrm{L}$ protein precipitation solution was added (7M Ammonium acetate, Tech \& Innovation, Seongnam, Korea) and centrifuged at $13,000 \mathrm{rpm} 20^{\circ} \mathrm{C}$ for $15 \mathrm{~min}$. After this, $600 \mu \mathrm{L}$ of supernatant was transferred to a new $1.5 \mathrm{~mL}$ tube and incubated at $65^{\circ} \mathrm{C}$ for $1 \mathrm{~h}$ after $10 \mu \mathrm{L}$ RNase solution was added $(10 \mathrm{mg} / \mathrm{mL}$, G-spin Total DNA extraction Kit, iNtRON Biotechnology, Korea). Subsequently, $600 \mu \mathrm{L}$ was added into the tube and centrifuged again $\left(13,000 \mathrm{rpm}, 20^{\circ} \mathrm{C}\right.$ for $\left.15 \mathrm{~min}\right)$. The solution was divided into another two $1.5 \mathrm{~mL}$ tubes, with each tube for $600 \mu \mathrm{L}$, and this was followed by adding $600 \mu \mathrm{L}$ isopropanol to each tube, inverting the sample and incubating at $-20^{\circ} \mathrm{C}$ for $1 \mathrm{~h}$. After that, it was centrifuged at $13,000 \mathrm{rpm}, 4^{\circ} \mathrm{C}$ for $10 \mathrm{~min}$, then the supernatant was discarded and $300 \mu \mathrm{L} 70 \% \mathrm{EtoH}$ was added to wash the DNA extraction. Finally, the sample was centrifuged at 13,000 $\mathrm{rpm}, 4^{\circ} \mathrm{C}$ for $5 \mathrm{~min}$, and supernatant was discarded, pellet was dried at room temperature for $1 \mathrm{~h}$, then $50 \mu \mathrm{L}$ Tris-EDTA (TE) buffer was added ( $1 \times$ TE buffer, PH 8.0, Tech \& Innovation, Korea) for storing.

Polymerase chain reaction and restricted fragment length polymorphisms

Primer sequences for the target gene $A D H 1 C$ were 5'CAGGGC TTAAAGATCCCAGA (forward), 3'-TAGCCAATGCTTGTC TCTCG (reverse), which was referenced from GenBank (accession number NC007304.4). ADH1C gene was amplified by $2 \times$ Taq polymerase chain reaction (PCR) premix kit (Solgent Co. Ltd, Daejeon, Korea) followed by using the T100 96-well Thermal
Cycler (Bio-Rad Laboratories Inc, Seoul, Korea): $95^{\circ} \mathrm{C}$ for $5 \mathrm{~min}$, 35 cycles of $30 \mathrm{~s}$ at $95^{\circ} \mathrm{C}, 30 \mathrm{~s}$ at $55^{\circ} \mathrm{C}, 1 \mathrm{~min}$ for $72^{\circ} \mathrm{C}$, and finally 5 min at $72^{\circ} \mathrm{C}$. The product of PCR was digested by BsII (New England Biolabs, Pickering, ON, Canada) for $3 \mathrm{~h}$, in which $\mathrm{C}$ allele was cut into 160-bp and 93-bp fragments [4]. Then, the type of $\mathrm{ADH} 1 \mathrm{C}$ was shown by the separation of electrophoresis according to a $2 \%$ agarose gel. The standard of ADH1C genotype was shown in Figure 1, in which TT type and TC type were expressed as lane 2 and lane 3, respectively.

\section{Beef carcass grading analyses in Korea}

The Korean beef carcass-grading system included quality and yield grade. In the quality grade, five acceptable levels $(1++, 1+$, $1,2,3$ ) were classified according to marbling score (intramuscular fat), lean meat color, fat color and texture of lean meat, and maturity of the exposed longissimus dorsi muscle at the thirteenth rib interface. The quality grade $1++$ was considered as the highest quality and grade 3 was the lowest quality. The yield grade included three types $(\mathrm{A}, \mathrm{B}, \mathrm{C})$ and was determined according to carcass weight, subcutaneous fat thickness, eye muscle area and meat quantity index. Yield grade $\mathrm{A}$ was the highest and $\mathrm{C}$ was the lowest. According to the previous study, yield grade was determined on the basis of estimated retail cut percentage and the equation for retail cut percent was that: retail cut $\%=65.8834-$ $(0.393 \times$ back fat thickness, $\mathrm{mm})+\left(0.088 \times\right.$ area of rib eye, $\left.\mathrm{cm}^{2}\right)-$ ( $0.008 \times$ cold carcass weight, $\mathrm{kg}$ ). Yield grade A, B, and C counted for the retail cut percentage higher than $69 \%, 69 \%$ to $66 \%$ and less than $66 \%$, respectively [7]. Back fat thickness was measured between the twelfth and thirteen ribs, maturity was determined by evaluating the color, shape and ossification of the bones and cartilage. Intramuscular fat or marbling score was based on beef marbling standard (BMS; 1 = devoid, 9 = very abundant). BMS 8 or 9 was for grade $1++, 6$, or 7 was for grade $1+, 4$, or 5 was for grade 1,2 , or 3 was for grade 2 and BMS 1 was for grade 3 beef

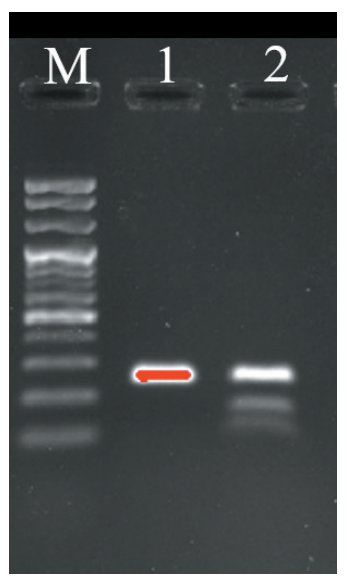

Figure 1. Agarose gel electrophoresis of alcohol dehydrogenase 1C (ADH1C) gene C. $-64 \mathrm{~T}>\mathrm{C}$ polymerase chain reaction-restriction fragment length polymorphism. Lane 1 is 100 bp plus DNA ladder, lane 2 is standard for TT type, lane 3 is standard for TC type. 
(KAPE; Korea Institute for Animal Products Quality Evaluation, 2011). The calculation formula of quality grade and yield grade in Table 4 were referred to the previous study in Hanwoo steers [7].

\section{Statistical analysis}

The result values were shown as least square means \pm standard error of the mean. The data of serum vitamin A were analyzed by Duncan's multiple range test using one-way and two-way analysis of variance (one-way and two-way ANOVA) in SPSS Version 21 for Windows (SPSS Inc., Chicago, IL, USA). The concentration of serum and genotype were in included in one-way ANOVA test, and the genotypexvitamin A interaction were included in two-way ANOVA test. The data of carcass traits were analyzed through Duncan's multiple range tests using a one-way ANOVA in SPSS Version 21 for Windows (SPSS Inc., USA). Significance was set at $\mathrm{p}<0.05$, and the trend was set at 0.1 .

\section{RESULTS AND DISCUSSION}

\section{ADH1C genotype and concentration of serum vitamin A} During the fattening period, vitamin A restriction was conducted in treatment by feeding the feedstuff which contained $0.89 \mathrm{IU} / \mathrm{g}$ vitamin A in study 1 . The concentration of vitamin A in the control group was at a high level $(8.89 \mathrm{IU} / \mathrm{g})$. At the beginning of the experimental period, the concentration of serum in treatment group and control group were in the similar level ( $p>0.05$ ) in Table 2. During the experimental period, concentration of serum vitamin A in the treatment group was decreased significantly during the experiment period $(\mathrm{p}<0.05)$ in Table 2 . The level of serum vitamin $\mathrm{A}$ in the control group did not show any change by feeding with a high level of vitamin A (8.89 IU/g). Previous studies also showed that serum vitamin A was reduced without the supplement of vitamin A in the diet $[8,9]$. Low serum vitamin A level also indicated the higher marbling score than high serum vitamin A during the fattening stage in Japanese Black Steers [10].

We found that $85 \%$ of Korean native steers in study 1 were TT type and $15 \%$ were TC type. However, we didn't find any CC type in the 60 steers. In study 2 , the ratio of TT type is $75 \%$, with $25 \%$ of 136 Korean native steers TC type, and we still did not find the CC type of $A D H 1 C$ gene. Totally we found 78\% TT type and $22 \%$ TC type in these steers which was showed in Table 3 . In terms of the concentration of serum vitamin A, there were no differ-
Table 3. Ratio of ADH1C genotype in Korean native steers (study 1 and 2)

\begin{tabular}{lccc}
\hline & TT type & TC type & CC type \\
\hline Experiment 1 & & & \\
$\quad$ Heads & 51 & 9 & 0 \\
Ratio (\%) & 85 & 15 & 0 \\
Experiment 2 & & & \\
$\quad$ Heads & 102 & 34 & 0 \\
$\quad$ Ratio (\%) & 75 & 25 & 0 \\
Total & & & \\
$\quad$ Heads & 153 & 43 & 0 \\
$\quad$ Ratio (\%) & 78 & 22 & 0 \\
\hline
\end{tabular}

ADH1C, alcohol dehydrogenase $1 \mathrm{C}$

ences between the ADH1C genotypes under a high vitamin $\mathrm{A}$ level condition. However, when the vitamin A was restricted, the TC type of $A D H 1 C$ gene showed a faster downtrend $(\mathrm{p}<0.1)$ in the serum vitamin A concentration than TT type, although it did not show a significant decrease. The previous research showed no significant results in the black Angus-cross steers during the vitamin A restriction period [4]. But this revealed the tendency that $\mathrm{TC}$ type of $\mathrm{ADH} 1 \mathrm{C}$ had the potential to achieve a lower level of serum vitamin $\mathrm{A}(\mathrm{p}<0.1)$.

\section{ADH1C genotype and carcass traits in Korean native}

Table 4. Effect of $A D H 1 C$ gene on carcass traits in Korean native steers during vitamin A restriction

\begin{tabular}{lrrc}
\hline & \multicolumn{1}{c}{ TT type } & \multicolumn{1}{c}{ TC type } & p value \\
\hline Back fat thickness $(\mathrm{cm})$ & $12.7 \pm 0.42^{1)}$ & $13.2 \pm 0.72$ & 0.952 \\
Eye muscle area $\left(\mathrm{cm}^{2}\right)$ & $86.8^{\mathrm{a}} \pm 0.94$ & $93.0^{\mathrm{b}} \pm 1.88$ & 0.002 \\
Carcass weight $(\mathrm{kg})$ & $411.0^{\mathrm{a}} \pm 5.04$ & $444.2^{\mathrm{b}} \pm 9.83$ & 0.002 \\
Meat quantity index & $64.8 \pm 0.29$ & $64.6 \pm 0.57$ & 0.771 \\
Marbling score & $5.2^{\mathrm{a}} \pm 0.16$ & $6.3^{\mathrm{b}} \pm 0.28$ & 0.001 \\
Meat color & $4.8 \pm 0.04$ & $4.8 \pm 0.07$ & 0.936 \\
Fat color & $3.0 \pm 0.02$ & $3.0 \pm 0.00$ & 0.320 \\
Texture & $1.2 \pm 0.04$ & $1.1 \pm 0.04$ & 0.125 \\
Grade of maturity & $2.1 \pm 0.03$ & $2.2 \pm 0.06$ & 0.410 \\
Quality grade & $34.0^{\mathrm{a}} \pm 0.81$ & $39.1^{\mathrm{b}} \pm 1.38$ & 0.002 \\
Yield grade $^{3)}$ & $187.1 \pm 6.81$ & $184.8 \pm 12.22$ & 0.870 \\
\hline
\end{tabular}

ADH1C, alcohol dehydrogenase $1 \mathrm{C}$

1) Standard error of the mean.

2) $50=1++, 40=1+, 30=1,20=2,10=3$.

3) $300=A, 200=B, 100=C$.

Values (mean \pm standard error of the mean) in a row bearing different superscripts differ significantly $(p<0.05)$.

Table 2. Effect of ADH1C genotype on the level of serum vitamin A during vitamin A restriction (study 1)

\begin{tabular}{|c|c|c|c|c|c|c|c|}
\hline & \multicolumn{2}{|c|}{ Control (8.89 IU/g feed vitamin A) } & \multicolumn{2}{|c|}{ Treatment (0.89 IU/g feed vitamin A) } & \multicolumn{3}{|c|}{ p-value } \\
\hline & TT type (25 heads) & TC type (6 heads) & TT type (26 heads) & TC type (3 heads) & G & VA & GxVA \\
\hline Initial & $136.6 \pm 4.31$ & $127.6 \pm 8.07^{1)}$ & $124.6 \pm 3.91$ & $133.4 \pm 19.90$ & 0.986 & 0.702 & 0.279 \\
\hline Experiment period & $137.4 \pm 5.31$ & $140.3 \pm 7.96$ & $111.1 \pm 5.00$ & $79.7 \pm 16.05$ & 0.149 & $0.000 * *$ & $0.083^{*}$ \\
\hline
\end{tabular}

ADH1C, alcohol dehydrogenase $1 C ; G$, genotype; VA, vitamin $A ; G \times V A$, genotype $\times$ vitamin $A$.

1) Standard error of the mean.

${ }^{*} p<0.1$, the value has the trend. ${ }^{* *} p<0.05$, the value is significant. 


\section{steers under vitamin A restriction}

Due to the restriction of vitamin A (0.93 IU/g vitamin A in the feedstuff), the carcass traits for experiment 2 were showed in Table 4. We obtained a higher value for eye muscle area, carcass weight, quality grade and marbling score (intramuscular fat) in TC types than in TT types $(\mathrm{p}<0.05)$. However, the opposite result was achieved when compared to the previous studies in which TT type steers had greater marbling score than TC type due to the vitamin A restriction [4]. And in another study on the vitamin A restriction in Angus-cross steers, vitamin A treatment at $75 \%$ of the NRC [11]-recommended level (2,200 IU/kg) revealed a significant difference, as TT type had greater IMF than TC type. But vitamin A treatment at 25\% and 50\% of NRC [11] recommend level $(2,200 \mathrm{IU} / \mathrm{kg})$ did not show this result, and vitamin A treatment at 25\% even showed that TC type steers trend higher than TT type steers [12]. Therefore, though restriction of vitamin $\mathrm{A}$ is important, the restriction level also becomes a more important factor in the study. Although it was unclear why TT and TC animals at the vitamin A restriction did not exhibit the same result compared with Black Angus crossbred steers, the different result in Korean native steers would be interpreted as the difference between varieties as well as the vitamin A restriction period.

At the same time, the previous study reported that the hepatic expression of $\mathrm{ADH} 1 \mathrm{C}$ mRNA was higher in TT steers than that in TC steers and CC steers under the condition of vitamin A restriction [4]. It can be inferred that the enzyme activity of TT type was higher than TC type and CC type in ADH1C gene. Based on the early research finding that retinol was oxidized to retinaldehyde by the enzyme similar to $\mathrm{ADH} 1$ [6], retinaldehyde was oxidized to retinoic acid by aldehyde dehydrogenase 1 (ALDH1) [13]. Furthermore, during the period of vitamin A restriction, RALDH1 has 3 times activity to transfer the retinaldehyde to retinoic acid [14], demonstrating that more retinoic acid will be synthesized in this process. Many previous studies have discovered that retinoic acid has an inhibitory effect on adipogenesis in 3T3-L1 cell [15-17]. As TT type of ADH1C gene has the potential to produce more retinoic acid than TC type, greater potential for the inhibition in the adipogenesis process could be inferred $[18,19]$. Thus, under the premise of vitamin A restriction in Korean native steers, TC type of $A D H 1 C$ gene was linked to higher marbling than TT type $(\mathrm{p}<0.05)$. Meanwhile, eye muscle area and carcass weight in TC type were higher than in TT type during the vitamin A restriction period $(\mathrm{p}<0.05)$. However, there were no significant differences in eye muscle area and carcass weight among the different types of $A D H 1 C$ gene according to the previous research $[4,12]$.

In conclusion, TC type of $A D H 1 C$ gene tended to reach lower serum vitamin A level during the vitamin A restriction period in Korean native steers. At the same time, when vitamin A was restricted in Korean native steers, the steers in TC type of $A D H 1 C$ gene had a much higher level of intramuscular fat than the steers in TT type.

\section{CONFLICT OF INTEREST}

We certify that there is no conflict of interest with any financial organization regarding the material discussed in the manuscript.

\section{ACKNOWLEDGMENTS}

This work was supported by Cooperation Research Project (PJ0100232), Rural Development Administration, Republic of Korea.

\section{REFERENCES}

1. Shiranita K, Hayashi K, Otsubo A, Miyajima T, Takiyama R. Grading meat quality by image processing. Pattern Recogn 2000;33:97-104.

2. Oka A, Maruo Y, Miki T, Yamasaki T, Saito T. Influence of vitamin A on the quality of beef from the Tajima strain of Japanese black cattle. Meat Sci 1998;48:159-67.

3. Gibb D, Van Herk F, Mir P, Loerch S, McAllister T. Removal of supplemental vitamin A from barley-based diets improves marbling in feedlot heifers. Canadian J Anim Sci 2011;91:669-74.

4. Ward AK, McKinnon JJ, Hendrick S, Buchanan FC. The impact of vitamin A restriction and $\mathrm{ADH} 1 \mathrm{C}$ genotype on marbling in feedlot steers. J Anim Sci 2012;90:2476-83.

5. Molotkov A, Fan X, Duester G. Excessive vitamin A toxicity in mice genetically deficient in either alcohol dehydrogenase Adh1 or Adh3. Eur J Biochem 2002;269:2607-12.

6. Molotkov A, Duester G. Genetic evidence that retinaldehyde dehydrogenase Raldh1 (Aldh1a1) functions downstream of alcohol dehydrogenase Adh1 in metabolism of retinol to retinoic acid. J Biol Chem 2003;278:36085-90.

7. Moon S, Hwang I, Jin S, Lee J, Joo S, Park G. Carcass traits determining quality and yield grades of Hanwoo steers. Asian-Australas J Anim Sci 2003;16:1049-54.

8. Pickworth CL, Loerch SC, Fluharty FL. Restriction of vitamin A and $\mathrm{D}$ in beef cattle finishing diets on feedlot performance and adipose accretion. J Anim Sci 2012;90:1866-78.

9. Gorocica-Buenfil MA, Fluharty FL, Loerch SC. Effect of vitamin A restriction on carcass characteristics and immune status of beef steers. J Anim Sci 2008;86:1609-16.

10. Adachi K, Kawano H, Tsuno K, et al. Relationship between serum biochemical values and marbling scores in Japanese Black steers. J Vet Med Sci 1999;61:961-4.

11. National Research Council (US). Subcommittee on beef cattle nutrition. Nutrient requirements of beef cattle. 7th rev. ed. Washington, DC: National Academy Press; 1996.

12. Krone KG, Ward AK, Madder KM, et al. Interaction of vitamin A supplementation level with ADH1C genotype on intramuscular fat in beef steers. Animal 2016;10:403-9.

13. Kiefer FW, Orasanu G, Nallamshetty S, et al. Retinaldehyde dehydrogenase 1 coordinates hepatic gluconeogenesis and lipid metabolism. Endocrinology 2012;153:3089-99. 
14. Napoli JL, Boerman MH, Chai X, Zhai Y, Fiorella PD. Enzymes and binding proteins affecting retinoic acid concentrations. J Steroid Biochem Mol Biol 1995;53:497-502.

15. Kim DM, Choi HR, Park A, et al. Retinoic acid inhibits adipogenesis via activation of Wnt signaling pathway in 3T3-L1 preadipocytes. Biochem Biophys Res Commun 2013;434:455-9.

16. Sagara C, Takahashi K, Kagechika H, Takahashi N. Molecular mechanism of 9-cis-retinoic acid inhibition of adipogenesis in 3T3-L1 cells. Biochem Biophys Res Commun 2013;433:102-7.

17. Berry DC, Noy N. All-trans-retinoic acid represses obesity and insulin resistance by activating both peroxisome proliferation-activated receptor beta/delta and retinoic acid receptor. Mol Cell Biol 2009;29: 3286-96.

18. Mizoguchi Y, Moriya M, Taniguchi D, Hasegawa A. Effect of retinoic acid on gene expression profiles of bovine intramuscular preadipocytes during adipogenesis. Anim Sci J 2014;85:101-11.

19. Amengual J, Ribot J, Bonet ML, Palou A. Retinoic acid treatment enhances lipid oxidation and inhibits lipid biosynthesis capacities in the liver of mice. Cell Physiol Biochem 2010;25:657-66. 